\title{
Different male mate location behaviour of the Glanville fritillary butterfly in different landscapes in the Tianshan Mountains, northwestern China
}

\author{
Yan Zhou, Chang Xu, Houqiang Chen, Dandan Zhang, Yu Long, Fengming Yan, \\ Chongren Xu \& Rongjiang Wang*
}

Zhou, Y., Xu, Chang, Chen, H., Zhang, D., Long, Y., Yan, F., Xu, Chongren, Wang, R. 2013: Different male mate location behaviour of the Glanville fritillary butterfly in different landscapes in the Tianshan Mountains, northwestern China. — Entomol. Fennica 24: 129-139.

In a previous study most males of the Glanville fritillary butterfly (Melitaea cinxia) were caught in valleys, whereas almost all females were distributed on slopes in the Tianshan Mountains, northwestern China. To help understand this phenomenon, male mate location behaviours were observed in different landscapes of the Tianshan Mountains. In valleys, males exhibited perching behaviour. On slopes, spatial distribution of males showed patrolling behaviour on meadows, but intermediate behaviour between perching and patrolling at forest edge. The temporal distribution of males also varied, being found on slopes from 7:00 to 18:00, but in valleys from 8:00 to 13:00 each day. Ambient temperatures were higher on slopes than those in valleys between 8:00 to 13:00. Males exhibited lower tolerance to high temperature than females, leading to the conclusion that valleys are more likely to be used by males as thermoregulation sites, rather than for mating.

Y. Zhou, College of Life Sciences, Peking University, Beijing 100871, P. R. China; College of Nature Conservation, Beijing Forestry University, Beijing 100083, P. R. China

Chang Xu, H. Chen, D. Zhang \& Y. Long, College of Life Sciences, Peking University, Beijing 100871, P. R. China

F. Yan, College of Life Sciences, Peking University, Beijing 100871, P. R. China; College of Plant Protection, Henan Agricultural University, Zhengzhou, Henan 450002, P. R. China

Chongren Xu, College of Life Sciences, Peking University, Beijing 100871, P. R. China; E-mail:xchr@pku.edu.cn

R. Wang, *corresponding author, College of Life Sciences, Peking University, Beijing 100871, P. R. China; E-mail: rjwang@pku.edu.cn 


\section{Introduction}

Male mate location behaviour in butterflies has been classified into two basic types, perching and patrolling; perching males sit and wait at a particular site (territory), rising to intercept passing females, while patrolling males spend most of their time in flight actively searching for females (Scott 1974). However, few empirical studies report butterfly species adopting specialized perching or patrolling behaviour but a large number of butterfly species adopt both perching and patrolling behaviours (e.g. Dennis \& Williams 1987, Alcock 1994, Wahlberg 2000, Ide 2004, Merckx \& van Dyck 2005, Takeuchi 2010).

Adoption of mate location behaviour in male butterflies is influenced by various biotic and abiotic factors. As male butterflies usually attempt to encounter more receptive females in locations with fewer rival males to increase the chance of mating, both abundance of females (Dennis \& Williams 1987, Ide 2004) and that of rival males (Alcock \& O’Neil 1986, Peixoto \& Benson 2009) greatly influence sites where males locate females and engage in subsequent mate location behaviour. In some butterfly species, individuals with different phenotypes (body size, wing color, etc.) exhibit different behaviours for locating females (van Dyck et al. 1997a, b, Hernández \& Benson 1998). The behaviour used also depends on a number of environmental factors, especially those affecting thermal condition (Willmer 1991). As ectotherms, the activity of butterflies is greatly constrained by ambient temperature. It has been reported that in several species male butterflies tend to adopt perching behaviour under low ambient temperature and patrolling behaviour under higher temperature (e.g. Wickman 1985, 1988). For some butterfly species, regular switching between different types of mate location behaviour has been reported as being due to diurnal change of ambient temperature (Ide 2010, Takeuchi 2010). In the butterfly Lycaena hippothoe (Linnaeus), diurnal change of ambient temperature resulted in different mate location behaviour of males, with a higher proportion of perching in the morning and of patrolling in the afternoon (Fischer \& Fiedler 2001). Other environmental factors, such as landform, which affect local ambient temperature, also influence mate location behaviour of male butterflies (Kemp \& Rutowski 2001, Dennis 2004, Dennis \& Sparks 2005). In the butterfly Chlosyne californica (Wright), males exhibit territorial defence of hilltop perch sites and patrolling behaviour on slopes (Alcock 1994). On the other hand, thermal conditions affect not only male behaviour but also the behaviour and distribution of females, which in turn influence the male mate location strategy (e.g. Dennis \& Shreeve 1988, Kemp \& Rutowski 2001). Therefore, male butterflies at a particular site will exhibit specific mate location behaviour based on distribution of receptive females and local environmental factors.

In this study we report on the male mate location strategy of the Glanville fritillary butterfly (M. cinxia (Linnaeus), Lepidoptera: Nymphalidae) in the Tianshan Mountains, northwestern China. In earlier studies, the mate location strategy of the Glanville fritillary has been reported in the populations of the Aland Islands in Finland and the Isle of Wight (U. K.), where both patrolling and perching behaviour occur (Bourn \& Warren 1997, Wahlberg 2000). In Åland Islands, males primarily perch for mate location (Wahlberg 2000), and on the Isle of Wight, males primarily exhibit patrolling to look for females (Bourn \& Warren 1997). Effect of ambient temperature might explain the difference of mate location strategy between Finland (average maximum temperature in June $17^{\circ} \mathrm{C}$ ) and U. K. (average maximum temperature in June $23^{\circ} \mathrm{C}$ ). Climatic conditions, especially daily temperature variation, differ greatly between these islands and high mountainous inland, which could result in different mate location strategy in the Tianshan Mountains. In a previous investigation (Zhou et al. 2012) in Nantaizi of the Tianshan Mountains, most male butterflies (63\% in 2004 and 53\% in 2005) were captured in valleys, despite an absence of the larval host plants (Veronica spicata) and with few nectar plants available. However, females were mostly found on meadow slopes (61\% in 2004 and $80 \%$ in 2005, Zhou et al. 2012). The difference between the distribution of males and females suggests specific behavioural patterns connecting these two locations in mate selection. We conducted a thorough investigation on the Glanville fritillary mate location strategy in the Tianshan Mountains in 2007 and 2008 in 
attempting to understand the mate location strategy in this area.

\section{Material and methods}

\subsection{Study site and species}

The study site, Nantaizi $\left(43.4^{\circ} \mathrm{N}, 87.2^{\circ} \mathrm{E}\right)$, is located in the Tianshan Mountains, Xinjiang, China. The elevation ranges from $1,700 \mathrm{~m}$ in the north to $2,200 \mathrm{~m}$ in the south. The whole area is about $10 \mathrm{~km}^{2}$ in size, with 8 large, and several small ridges and a long, flat tableland crossing the entire area (Fig.1). Slopes at higher elevation and the north-facing slopes are covered mostly by spruce forest (Picea schrenkiana Fischet Mey.). South-facing slopes have largely bare ground, while other slopes have dry meadows, which are home to $V$. spicata, the host plant of the Glanville fritillary. In valleys, the ground is covered by sparse grass and bushes. In Nantaizi, the Glanville fritillary has one generation per year with adults flying from late May to late June.

\subsection{Observations of different types of behaviour}

We observed male behaviour both on slopes and in valleys in Nantaizi. We chose a $150 \mathrm{~m}$-long valley and two east-facing slopes for behavioural observations (Fig. 1). As butterflies exhibited different patterns of behaviour between forest edge (with forest shadow) and on slope meadows, we separated records of behaviour at forest edges from those on slope meadows. During the flight season, we marked as many butterflies as possible with a unique number on the both sides of the

Fig. 1. Location of the valley and slopes for observations of Glanville fritillary behaviour in Nantaizi, Tianshan Mountains, China. - a. Details of the surroundings of the valley of this study. The valley is marked with grey wide lines, and $\mathrm{H} 1$ and $\mathrm{H} 2$ represent the name of sub-areas nearby the valley. $-b$. The whole study area with the valley and slopes marked. $-c$. The details of the slopes of this study. $\mathrm{H} 2-17$ and $\mathrm{H} 2-\mathrm{X} 9$ represent the meadows on slopes. wing, so that we could recognize the marked individuals without capture.

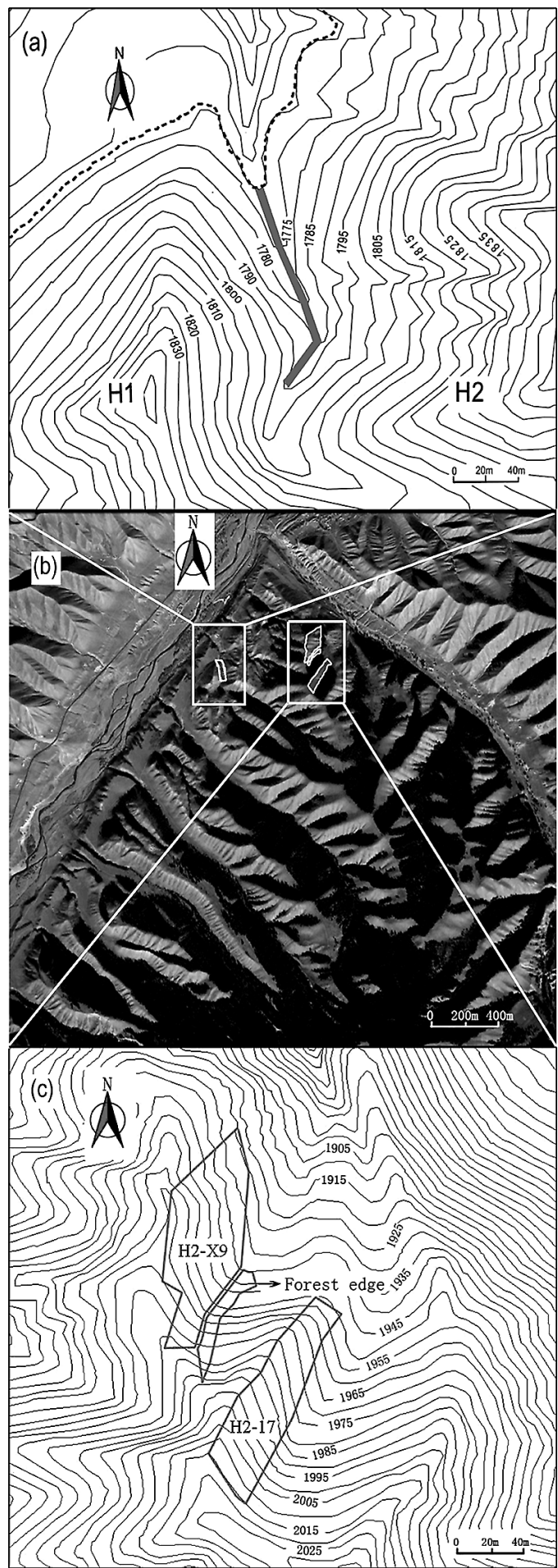


When weather conditions permitted, we started fieldwork from 7:00 on the slopes and from 8:00 in the valley. We started observation and recording behaviour of each male using a digital recorder whenever a male was encountered, and continued until it flew away, i.e. we did not relate the starting point of observations to any specific stage in time or behaviour. Daily observations were concluded when no further butterfly activity was observed (18:00 on the slopes, and 14:00 in the valley), or if weather conditions did not permit flight. Based on the observations, we classified the male behaviour into the following 5 types:

(1) Waiting: Staying on plants or the ground.

(2) Inspection: Spontaneous flight without interaction with other individuals.

(3) Chasing: Horizontal flight to chase other species.

(4) Fighting: Conspicuous, intensive, ascending circling flight between two conspecific males (resident and invader), in which the 'loser' flies away, and the 'winner' returns.

(5) Mating: Mating behaviour between male and female, as well as attempted mating behaviour.

However, because we focused on mate location strategy, the durations of successful matings were not included in the analysis.

We conducted the valley observations from 27.V. to 1.VII.2007 and from 27.V. to 23.VI. 2008. The bottom of the valley is approximately 2 $\mathrm{m}$ wide, so for the convenience of recording, we divided the whole valley into 75 two meter segments, and marked each segment with a visible flag, so that the position and inspection area of the male was easy to observe. Behaviour of male butterflies on the slopes was observed from 27.VI. to 23.VI.2008. It is much harder to record the position and inspection area of butterflies on the slopes.

We noted the duration of each behaviour for each male observed and combined that with data including the start/finish time of the observation, the position of butterfly, the outcome of any fighting, and the reason for leaving the territory. To avoid statistical bias, we excluded observations with less than 5 min and with less than 5 behavioural records.

\subsection{Measurement of ambient temperature}

As ambient temperature is a key environmental factor influencing mate location strategy in butterflies, we recorded the daytime ambient temperature in the valley and on one slope, respectively, for all our observations in 2008. The thermometer was placed about $1 \mathrm{~m}$ above the ground and the ambient shade temperature at intervals of $30 \mathrm{~min}$ was recorded.

\subsection{High temperature tolerance of butterflies}

We considered that the influence of ambient temperature on mate location strategy is possibly related to the difference in tolerance of high temperatures between males and females, so we studied the question in the laboratory. One 3-day old butterfly was placed in an incubator with $55^{\circ} \mathrm{C}$, and then the exact time was recorded of each individual when it died. A shorter killing time means lower tolerance of high temperature. Nine individuals of each sex were used for the study.

\subsection{Statistical analyses}

All statistical analyses were conducted with SPSS program version 17.0 (SPSS Inc. 2009). To estimate the duration of guarding territory, the cumulative distribution of the duration of observations was plotted with intervals of 1 min and a curve fit was obtained. Expected duration of guarding territory was calculated through the curve formula when the cumulative percentage was 1 . To compare estimated duration of guarding territory from different datasets, a general linear model was used, with the duration of observation as a covariate.

For tests of the datasets of territory size and percentage of each behavioural type, MannWhitney test was used when the dataset was not normally distributed, and $t$ test was used for normally distributed dataset. Kruskal-Wallis test was used in comparisons of the percentage of each behavioural type in the three landscapes. 


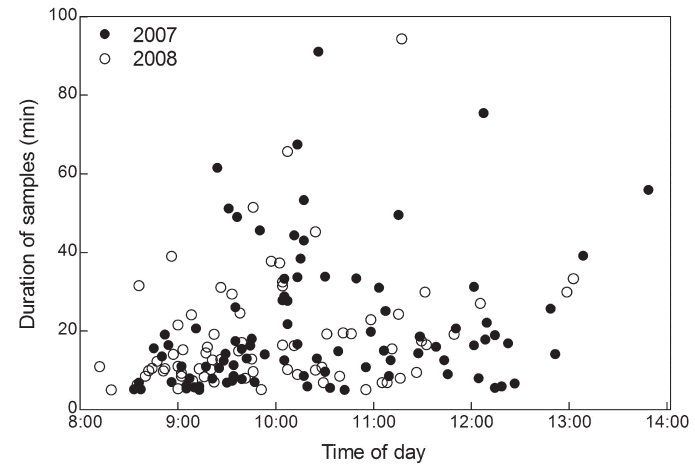

Fig. 2. The finish time and the duration of observations in the valley in 2007 and 2008.

\section{Results}

\subsection{Behaviour in the valley}

We obtained 91 and 72 records of behaviour in the valley in 2007 and 2008, respectively. Butterflies were usually found during 8:00 and 13:00. The male butterflies normally stayed on plants or on the ground. In the case of no other insect flying by, males spontaneously took flight to inspect an area after waiting for several minutes, then returned close to the start and resumed waiting. The inspection area is considered to be the male's territory (Takeuchi \& Imafuku 2005a). When an insect flew through a male's territory, it took flight and approached the invader. If the invader was another species, the male flew after the invader until it left its territory. If the invader was a conspecific male, fighting broke out, which typically resulted in the invader to lose and leave. If the invader was a female of the Glanville fritillary, the male flew after her in attempt to mate. After a period of guarding the territory with neither of the above behaviours being observed, the male typically flew away spontaneously.

\subsubsection{Duration of territorial guarding}

The duration of observations of territorial guarding ranged from 5 to 94 min (Fig. 2). We randomly located a male and started an observation, so the starting time of an observation was randomly distributed in the whole of the guarding territory, and the cumulative distribution of the

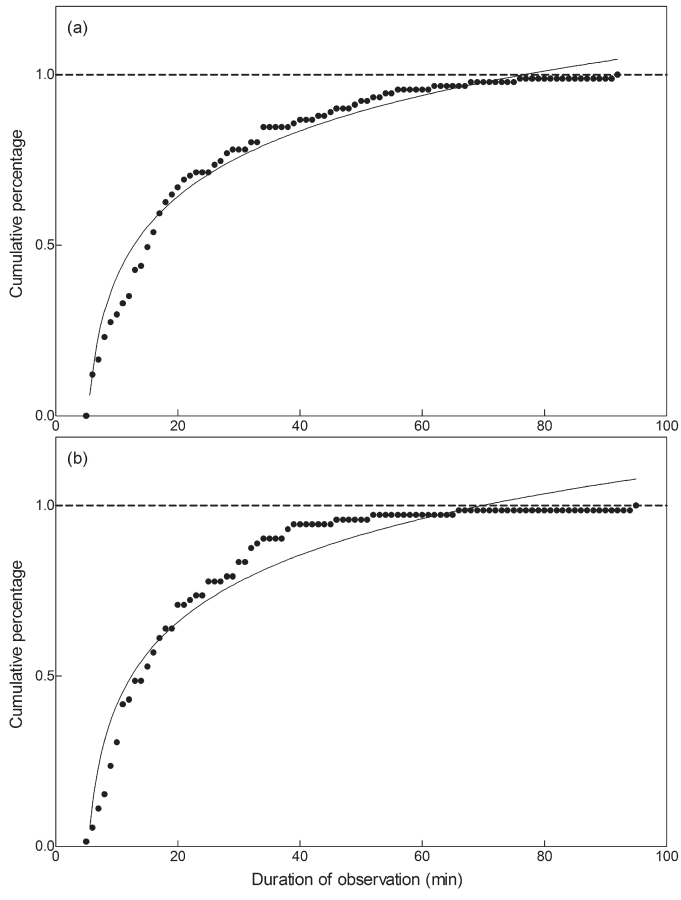

Fig. 3. The relationship between duration of observations of territorial guarding and cumulative percentage of observations in the valley. - a. 2007. - b. 2008. The dots represent the cumulative percentage of durations of observation with intervals of $1 \mathrm{~min}$. The black line represents the fit curve. The cross between the straight line at $100 \%$ cumulative percentage and the fit curve indicates the expected duration of guarding territory.

duration of observations should fit thus a logarithmic curve (Fig. 3). The datasets of both years fitted well to a logarithmic curve, with the coefficient of determination $\left(R^{2}\right) 0.930$ and 0.904 for 2007 and 2008, respectively. From the fitted curves, we estimated the expected duration of guarding territory as $76.4 \mathrm{~min}$ (with $95 \%$ confidence interval 73.7 79.7) and $70.3 \mathrm{~min}$ (66.4 75.3 ) in 2007 and 2008 respectively, which were not significantly different (General linear model, $\left.F_{1,180}=0.737, P=0.392\right)$.

\subsubsection{Time allocation for each type of behaviour}

In 2007 and 2008, we recorded behaviour types in the valley 12,277 times. Mating behaviour was observed only 11 and 7 times in 2007 and 2008 


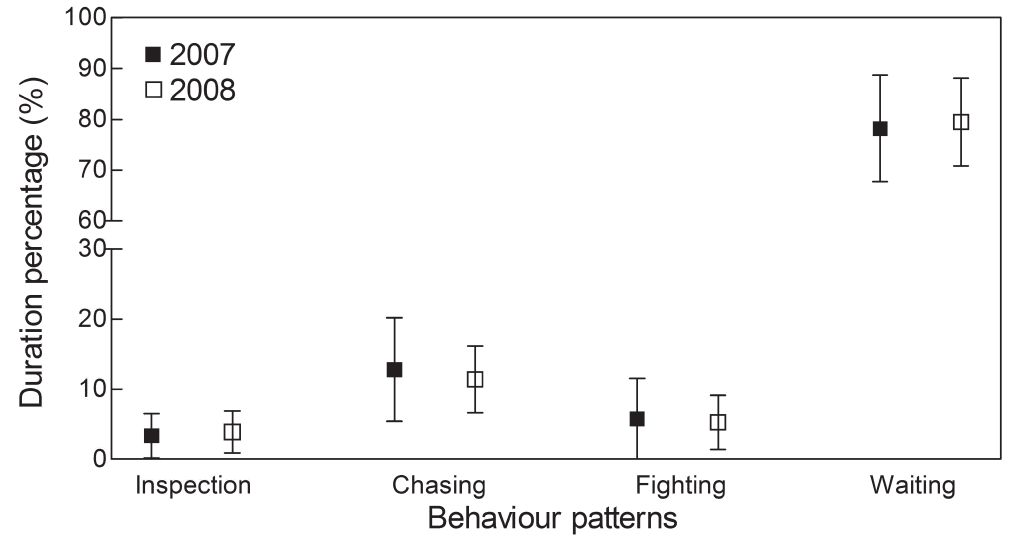

Fig. 4. Means ( \pm S. D.) of duration of behaviour types of male butterflies in the valley in 2007 and 2008. respectively, and 2 females finally mated with males in 2007. Males spent about 10 seconds to chase females, finally successfully mating or leaving the territory. In comparison with other behaviour types, the time spent on mating behaviour was trivial. Time allocation for different types of behaviour was similar for 2007 and 2008 , with males spending about $80 \%$ of the time waiting, about $13 \%$ chasing, and the remaining time for inspection and/or fighting (Fig. 4).

\subsubsection{Territory size}

The inspection area of a male butterfly in spontaneous flight is normally considered its territory (Takeuchi \& Imafuku 2005a). We recorded 84 and 72 territories in the valley in 2007 and 2008, respectively. Territory size varied from 1 to 15 segments $\left(=4-60 \mathrm{~m}^{2}\right)$, with a mean of 6 segments $\left(24 \mathrm{~m}^{2}\right)$ in both 2007 and 2008, and there was no significant difference between 2007 and 2008 (Mann-Whitney test, $Z=-0.437, P=0.663$ ).

\subsubsection{Outcome of fighting}

We observed 495 cases of fighting in the valley in 2007 and 345 in 2008. In 84 cases in 2007 and 65 in 2008 the fighting ended in a draw, in which both males returned to the start point, but peace was soon broken as one male took flight and began fighting again until a winner emerged. In 2007 and 2008, the residents of territory won respectively $75.7 \%$ and $73.9 \%$ of the fights (Table 1).

\subsection{Behaviour on slopes}

In the investigation in 2008, we found butterflies on the slopes from 7:00 to 18:00. We obtained records of 18 individuals on the meadows and 6 individuals at the forest edge after excluding the observations with less than 5 min duration and with less than 5 behavioural records. For comparison, 72 observations in the valley in 2008 were used in this analysis. Such a great difference in the number of observations between the valley and the slopes was related to the different density and behaviour of male butterflies. The density of males was considerably lower on slopes than in the valley, so that the chance of meeting males was greatly decreased. On the other hand, on the slopes male butterflies usually spent most time on flying in a relatively larger area (see the following result), so it became hard to track a male for longer than $5 \mathrm{~min}$.

On the slopes, the inspecting male normally patrolled a large area and did not return to the

Table 1. The outcome of fights of males in the valley.

\begin{tabular}{lllll}
\hline & N & Resident wins & Resident loses & Draw \\
\hline 2007 & 495 & $375(75.7 \%)$ & $36(7.3 \%)$ & $84(17.0 \%)$ \\
2008 & 345 & $255(73.9 \%)$ & $25(7.3 \%)$ & $65(18.8 \%)$ \\
\hline
\end{tabular}


Fig. 5. Means $( \pm$ S. D.) of duration of behaviour types of male butterflies in different landscapes in 2008.

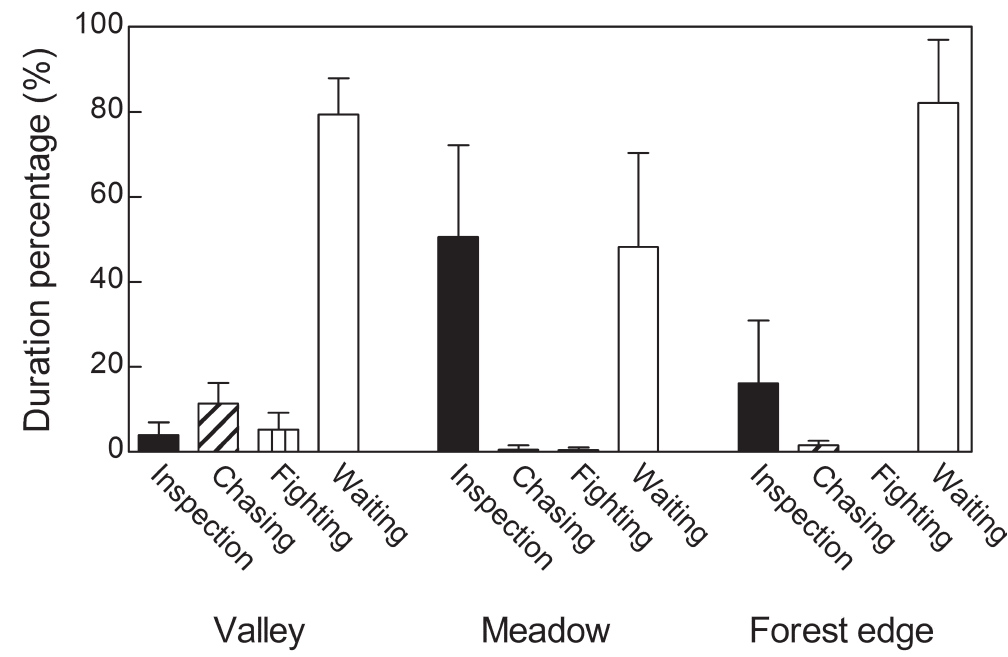

diurnal pattern through affecting solar radiation. In the early morning, the ambient temperature increased rapidly on the east-facing meadows due to direct solar radiation, while the valley is sheltered in mountain shadow. Ambient temperature in the valley increases with the sun moving south and reaches maximum in the afternoon, while it gradually decreases with decreasing solar radiation on the meadow. Therefore, it is plausible that the ambient temperature exhibits a similar diurnal pattern in the days suitable for observing butterflies as that in 10.VI. (Fig. 6).

\subsection{High temperature tolerance of butterflies}

In the study of high temperature tolerance, the average killing time of male butterflies was $2.4 \mathrm{~min}$, significantly shorter than that of females (4.1 $\min ; t$ test, $t_{16}=2.535, P=0.022$ ), i.e. females had a higher tolerance to high temperature than males.

\section{Discussion}

In Nantaizi, male butterflies of the Glanville fritillary exhibited greatly different behaviours between different landscapes (Fig. 5). In valleys, males occupied a small area, expelling other species of butterfly, fighting with conspecific males, and pursuing females for copulation. This is perching behaviour as described by Scott (1974), landscape plays an important role in affecting its 


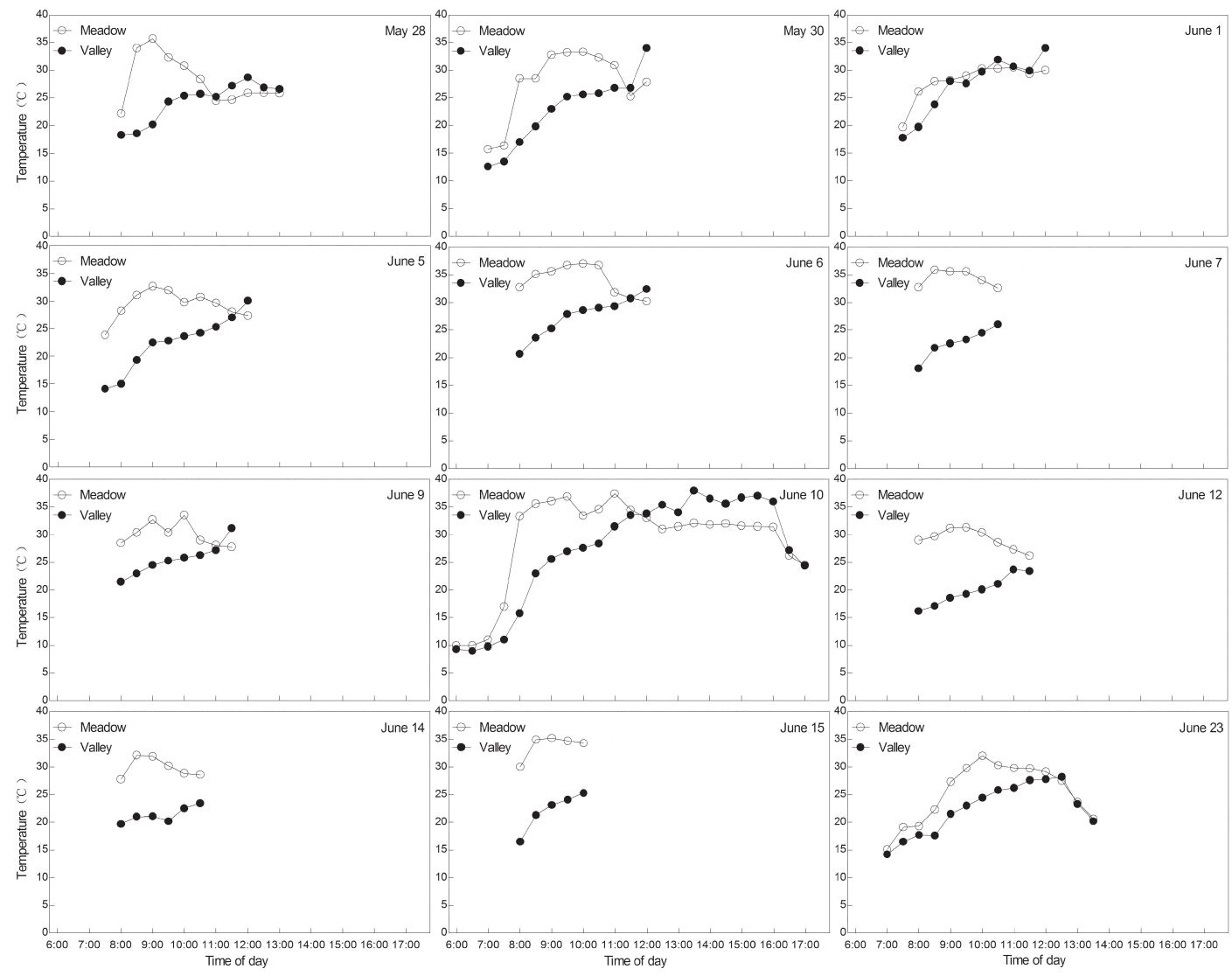

Fig. 6. The daily ambient temperatures on the slope meadow and in the valley in 2008.

and appears associated with territorial defence (Rutowski 1991). Unlike those in valleys, male butterflies seldom chased other species and fought with conspecific males on slope meadows, and spent more than $50 \%$ of time on inspection flights. According to Scott's (1974) definition, this is patrolling behaviour. At the forest edge of slopes, male butterflies allocated a similar time to waiting as those in the valleys, although they spent more time on inspection than chasing and fighting (Fig. 5). Therefore, intermediate behaviour between perching and patrolling at forest edge of slopes appears the norm. However, because there are rather few records at the forest edge, this conclusion should be treated cautiously.

It has been reported that ambient temperature is crucial for the choice of mate location behaviour (e.g. Ravenscroft 1994, Dennis \& Sparks 2005, Ide 2010). In several species of butterfly, males tend to adopt patrolling behaviour in an environment with high ambient temperature, whereas under relatively cooler temperatures, they tend to adopt perching behaviour (Wickman 1985, 1988, van Dyck \& Matthysen 1998). Our observation is consistent with these studies. In Nantaizi, from 8:00 to 13:00 when males are found in valleys, the ambient temperatures are usually higher on slopes than those in valleys (Fig. 6), and male butterflies exhibited patrolling and perching behaviour on slopes and in valleys, respectively.

In our previous investigations in 2004 and 2005 , most males were captured in valleys and most females were found on slopes (Zhou et al. 2012). To explain this difference, we suggested two possible explanations: first, valleys were used as mating sites, where males and receptive females congregate for mating; alternatively, the environmental conditions on slopes were unfa- 
vourable for males, although males must move to slopes for mating (Zhou et al. 2012). In the present study, 18 females were found in the valley in 2007 and 2008, of which only 2 females were receptive. In comparison, we caught 71 females on the slopes during 2008 (personal observation). Such limited mating chances may explain the difference between the perching behaviour in valleys in this study and that observed for other butterflies. In several butterflies with territorial behaviour, males usually occupy the territory for a few days (e.g. Cordero \& Soberón 1990, Fischer \& Fiedler 2001, Takeuchi \& Imafuku 2005b). However, in the present study, male butterflies defended territory for only about $70 \mathrm{~min}$ in the valley, and all males finally left the valley after 13:00 every day in both years. Furthermore, other studies have reported that for butterflies which defend a territory, residents usually win more than $90 \%$ cases of fighting (see Kemp 2000, Kemp \& Wiklund 2001, Takeuchi \& Imafuku 2005a), whereas in this study the winning percentage of residents in the valley is lower (about $75 \%$, Table 1). More importantly, because fewer females were found in valleys, the first hypothesis became unsustainable, i.e. it is impossible that males and females congregate in valleys for mating.

Alternatively, which environmental factor limits the activity of males on slopes? As ectotherms, the activity of butterflies is greatly constrained by ambient temperature, so we examined carefully the difference of ambient temperature between valleys and slopes. We noticed that males regularly occupy the valley from 8:00 to 13:00 daily, and during this period the ambient temperatures were usually higher on slopes than in valleys (Fig. 6). In the present study, it was also found that male butterflies exhibit a lower tolerance to high temperature than females. Therefore, it is reasonable to consider higher ambient temperature on slopes as the factor that limits male activity there. It is suggested that males could not bear the higher ambient temperature on slopes, and so have to move to valleys with relatively cooler temperatures. Taking low mating chance into consideration, valleys are more likely to be used as thermoregulation sites for males, rather than mating sites.

It is interesting to analyse the relationship be- tween the mate location strategy on slopes and in valleys. There is a possibility that males occupying valleys do not move to slopes, but instead, they are active from 8:00 to 13:00 daily when the ambient temperature is suitable, and hide somewhere during other periods with unfavourable thermal conditions. However, three pieces of evidence make this unlikely. First, we spent considerable effort on observations in the valley not only from 8:00 to 13:00 daily, but also before 8:00 and after 13:00. We did not find males either before 8:00, or after 13:00. Secondly, nearly half of recaptured male butterflies (40/89) were found both on slopes and in valleys in the mark-releaserecapture study in 2005. Finally, one cloudy day in 2009, the ambient temperature did not exceed $30^{\circ} \mathrm{C}$ on slopes until 12:00, and we located butterflies only on slopes and not in the valley in spite of the ambient temperature being suitable for flight. This single observation implies that males are forced to valleys because of the higher temperatures on slopes. Therefore, it is possible that almost all male butterflies occupying valleys came from slopes, since almost all males were found either on slopes or in valleys (Zhou et al. 2012).

In Nantaizi, the daily behaviour of Glanville fritillary males seems to have the following pattern. In the early morning, the sun sheds light on east-facing slopes and the ambient temperature on slopes increases quickly, while the ambient temperature is quite low in valleys sheltered in mountain shadow (Fig. 6). In the morning, the ambient temperature on slopes is typically around $30^{\circ} \mathrm{C}$, or even higher (Fig. 6). Under these conditions males tend to adopt patrolling behaviour. Male butterflies exhibit lower tolerance to high temperature than females, which limits their time on slopes even though there are more chances for mating on the slopes. Males with lower tolerance have to leave the slopes and move to sites with relatively lower ambient temperature, such as valleys, while those with relatively higher tolerance still attempt to patrol on slopes. In the morning, the ambient temperature is about $20-25^{\circ} \mathrm{C}$ in valleys (Fig. 6), suitable for males as sheltering sites (Clench 1966). In such cooler environments, males adopt perching behaviour as in those butterflies that have been studied previously (e.g. Wickman 1985, van Dyck \& Matthysen 1998, Merckx \& van Dyck 2005). After 13:00, the am- 
bient temperature in valleys increases higher than that on slopes (Fig. 6), which forces them to leave. Although we have not directly observed where the males move to, it is possible that they return to slopes, as the slopes will be sunlit first next morning. Further studies obtaining direct observation of daily movement of males between valleys and slopes will help support our conclusions.

A question remains: why should males migrate into valleys rather than forest edges for avoiding high temperatures? The forest edge is close to meadows, where there are more mating possibilities, so it seems males ought to prefer forest edge rather than valleys for moderate body temperature. Indeed, some males did select forest edges as sheltering sites. However, more males moved to valleys for decreasing body temperature. One possible explanation is that the environment of forest edge is unstable. Male butterflies usually utilize the $2 \mathrm{~m}$ wide zone of the forest shadow. In this zone, hot air flow from the meadow and cooler airflow from the forest shadow mix and consequently, while the temperature is relatively low it can fluctuate and the airflow is unstable. Another possible explanation is that the size of forest edge is so limited that the density of males may become too high, if all males on meadow slopes seek shelter in forest edges. Future work should help clarify this matter.

Acknowledgements. We thank Yuan Liu, Zijuan Cao, and Maolin Zhang for help in the field, and Zhenyuan Yan for help in preparing for maps and data analysis. We thank Prof. Peter Bridgewater, Chair of United Kingdom Joint Nature Conservation Committee, for revising language of the manuscript. We especially thank two anonymous reviewers for a lot of helpful comments. This work was funded by the grants 30470286, 30670332 and the ChinaFinland Collaboration Project 30211130505 from the National Natural Science Foundation of China, and the project 6082012 supported by Beijing Natural Science.

\section{References}

Alcock, J. 1994: Alternative mate-locating tactics in Chlosyne californica (Lepidoptera, Nymphalidae). - Ethology 97: 103-118.

Alcock, J. \& O’Neill, K. M. 1986: Density-dependent mating tactics in the grey hairstreak, Strymon melinus (Lepidoptera, Lycaenidae). — Journal of Zoology 209: 105-113.
Bourn, N. A. D. \& Warren, M. S. 1997: Species action plan. Glanville Fritillary Melitaea cinxia. Butterfly Conservation Society, Colchester, Essex, UK. 7 pp.

Clench, H. K. 1966: Behavioral thermoregulation in butterflies. - Ecology 47(6): 1021-1034.

Cordero, C. R. \& Soberón, J. 1990: Non-resource based territoriality in males of the butterfly Xamia xami (Lepidoptera, Lycaenidae). - Journal of Insect Behavior 3: 719-732.

Dennis, R. L. H. 2004: Landform resources for territorial nettle-feeding Nymphalid butterflies, biases at different spatial scales. - Animal Biodiversity and Conservation 27 : $37-45$.

Dennis, R. L. H. \& Shreeve, T. G. 1988: Hostplant-habitat structure and the evolution of butterfly mate-locating behaviour. - Zoological Journal of the Linnean Society 94 : $301-318$.

Dennis, R. L. H. \& Sparks, T. H. 2005: Landscape resources for the territorial Nymphalid butterfly Inachis io, Microsite landform selection and behavioral responses to environmental conditions. - Journal of Insect Behavior 18: 725-742.

Dennis, R. L. H. \& Williams, W. R. 1987: Mate location behaviour of the large skipper butterfly Ochlodes venata, flexible strategies and spatial components. Journal of Lepidopterists' Society 41: 45-64.

Fischer, K. \& Fiedler, K. 2001: Resource-based territoriality in the butterfly Lycaena hippothoe and environmentally induced behavioural shifts. - Animal Behaviour 61: 723-732.

Hernández, M. I. \& Benson, W. W. 1998: Small-male advantage in the territorial tropical butterfly Heliconius sara (Nymphalidae), a paradoxical strategy? - Animal Behaviour 56: 533-540.

Ide, J. Y. 2004: Diurnal and seasonal changes in the matelocating behavior of the satyrine butterfly Lethe diana. — Ecological Research 19: 189-196.

Ide, J. Y. 2010: Weather factors affecting the male-locating tactics of the small copper butterfly (Lepidoptera, Lycaenidae). - European Journal of Entomology 107: 369-376.

Kemp, D. J. 2000: Contest behavior in territorial male butterflies, does size matter? - Behavioral Ecology 11: 591-596.

Kemp, D. J. \& Rutowski, R. L. 2001: Spatial and temporal patterns of territorial mate locating behaviour in Hypolimnas bolina (L.) (Lepidoptera, Nymphalidae). Journal of Natural History 35: 1399-1411.

Kemp, D. J. \& Wiklund, C. 2001: Fighting without weaponry, a review of male-male contest competition in butterflies. - Behavioral Ecology and Sociobio$\operatorname{logy}$ 49: 429-442.

Merckx, T. \& van Dyck, H. 2005: Mate location behaviour of the butterfly Pararge aegeria in woodland and fragmented landscapes. — Animal Behaviour 70: 411416.

Peixoto, P. E. C. \& Benson, W. W. 2009: Seasonal effects of density on territory occupation by males of the satyrine butterfly Paryphthimoides phronius (Butler 1867). - Journal of Ethology 27: 489-496. 
Ravenscroft, N. O. M. 1994: Environmental influences on mate location in male chequered skipper butterflies, Carterocephalus palaemon (Lepidoptera, Hesperiidae). - Animal Behaviour 47: 1179-1187.

Rutowski, R. L. 1991: The evolution of male mate-locating behavior in butterflies. - The American Naturalist 138: 1121-1139.

Scott, J. A. 1974: Mate-locating behaviour of butterflies. - American Midland Naturalist 91: 103-117.

SPSS Inc. 2009: PASW Statistics 17.0. SPSS Inc., Chicago, Illinois.

Takeuchi, T. 2010: Mate-locating behavior of the butterfly Lethe diana (Lepidoptera, Satyridae), Do males diurnally or seasonally change their mating strategy? Zoological Science 27: 821-825.

Takeuchi, T. \& Imafuku, M. 2005a: Territorial behaviour of Favonius taxila (Lycaenidae), territory size and persistency. - Journal of Research on the Lepidoptera 38: 69-66.

Takeuchi, T. \& Imafuku, M. 2005b: Territorial behavior of a green hairstreak Chrysozephyrus smaragdinus (Lepidoptera, Lycaenidae), Site tenacity and wars of attrition. - Zoological Science 22: 989-994.

van Dyck, H. \& Matthysen, E. 1998: Thermoregulatory differences between phenotypes in the speckled wood butterfly, hot perchers and cold patrollers? - Oecologia 114: 326-334.

van Dyck, H., Matthysen, E. \& Dhondt, A. A. 1997a: Mate-locating strategies are related to relative body length and wing colour in the speckled wood butterfly Pararge aegeria. - Ecological Entomology 22: 116120.

van Dyck, H., Matthysen, E. \& Dhondt, A. A. 1997b: The effect of wing colour on male behavioural strategies in the speckled wood butterfly. - Animal Behaviour 53: 39-51.

Wahlberg, N. 2000: Comparative descriptions of the immature stages and ecology of five Finnish melitaeine butterfly species (Lepidoptera, Nymphalidae). Entomologica Fennica 11: 167-174.

Wickman, P. O. 1985: The influence of temperature on the territorial and mate locating behaviour of the small heath butterfly, Coenonympha pamphilus (L.) (Lepidoptera, Satyridae). - Behavioral Ecology and Sociobiology 16: 233-238.

Wickman, P. O. 1988: Dynamics of mate-searching behaviour in a hilltopping butterfly, Lasiommata megera, The effects of weather and male density. - Zoological Journal of the Linnean Society 93: 357-377.

Willmer, P. 1991: Thermal biology and mate assquistion in ectotherms. - Trends in Ecology and Evolution 6: 396-399.

Zhou, Y., Cao, Y.D., Chen, H.Q., Long, Y., Yan, F.M., Xu, C.R. \& Wang, R.J. 2012: Habitat utilization of the Glanville fritillary butterfly in the Tianshan Mountains, China, and its implication for conservation. Journal of Insect Conservation 16: 207-214. 